\title{
A LUTA DOS APYÃWA PARA MANTER SUA LINGUA MATERNA VIVA
}

Gilson Ipaxi'awyga Tapirapé ${ }^{1}$

\section{IMAATOREJXẼ̃WA}

Ã te'omara a'era mõ akome'o marygato Apyãwa axe'ega magyãwa. Iexagakãta maira xe'ega pe apyãwa xe'ega mamarapãwa. Ikome'owo marama'eãra gỹ te'omara maira mama'ekwera Apyãwa xe'ega pe erakãwa, xe'ega maxywatyãwa ramõ. Ã maragetã te'omara pe ikome'opyra a'era mõ kwee apyyk wekawo Apyãwa marymaryn kaãjpe, xe'exe'egãjpe. Niwaxãj maira xe'ega axyywaatỹ ramõ, axe tanã wetepe ee xeret'omata ekwe xiape'a ikeãwa.

XE'EGETEAWYMA: Apyãwa axe'ega magyãwa. Maira xe'ega imamarapãwa. Maira mama'ekwera rerakãwa. Xe'ega magyãwa.

\section{RESUMO}

Este artigo, resultado de uma pesquisa qualitativa, discute situação sociolinguística Apyãwa, tendo por objetivo analisar o empréstimo e a invasão da língua portuguesa, discutindo também o trabalho dos professores Apyãwa na criação de novas palavras, no sentido de fortalecer o uso da língua Apyãwa. As informações apresentadas foram coletadas através das observações participativas nos eventos da comunidade e reuniões nas aldeias. Como conclusão, aponto a necessidade de ampliar a discussão sobre a questão linguística para debater a forte entrada de português na fala.

PALAVRAS-CHAVE: Realidade sociolinguística. Empréstimo e Invasão da língua portuguesa. Criação de Novas palavras. Uso da língua Apyãwa.

1 Licenciado no Curso de "Educação Intercultural" (Ciências da Linguagem) pela Universidade Federal de Goiás e Especialista em "Educação Intercultural e Transdisciplinar: Gestão Pedagógica”, pela mesma Universidade. É aluno do Curso de Pós-Graduação (Mestrado) em Letras e Linguística, também da UFG. Aldeia Wiriaotãwa, MT, Brasil. E-mail: gilson-tapirape@hotmail. com. 


\section{ABSTRACT}

This article, the result of a qualitative research, discusses sociolinguistic situation Apyãwa, aiming to analyze the loan and the invasion of the Portuguese language. However, it also discusses Apyãwa teachers' work in creating new words, in order to strengthen the use of Apyãwa language. The information presented was collected through participatory observations at community events and village meetings. As a conclusion, I point out the need to expand discussion on linguistic issues to discuss the strong entry of Portuguese into speech.

KEYWORDS: Sociolinguistic Reality. Loan and Invasion of the Portuguese language. Creation of New Words. Use of the language Apyãwa.

\section{Introdução}

Este texto apresenta um breve estudo sociolinguístico do povo Apyãwa, focalizando de modo especial o uso da língua nas comunidades e um importante processo de luta vivenciado nos momentos atuais em relação à forte entrada de língua portuguesa. Visa discutir questões de empréstimos e a invasão do português na língua Apyãwa. O trabalho é resultado da minha pesquisa no período de 2017 nas aldeias Apyãwa.

Os Apyãwa, conhecidos como Tapirapé, são falantes da língua Tapirapé, pertencente à Família Tupi-Guarani do Tronco Tupi. Atualmente, possuem dois territórios regularizados, a Área indígena Tapirapé/Karajá e a Terra Indígena Urubu Branco. Ambas localizam-se no estado de Mato Grosso. A pesquisa se centra nesta última, onde se concentra a maior parte da população distribuída em sete aldeias: Tapi' itãwa, Myryxitãwa, Akara'ytãwa, Tapiparanytãwa, Towajaatãwa, Wiriaotãwa e Inataotãwa. Na primeira, há uma única aldeia Apyãwa, denominada Majtyritãwa, onde também estão duas aldeias Karajá: Itxala e Hawalora.

A população Apyãwa soma hoje, aproximadamente, 850 pessoas, que são habitantes dessas aldeias acima mencionadas. Todos falam a língua Apyãwa como primeira língua e a grande maioria fala também o português como segunda língua. Em algumas famílias, no caso de casamento interétnico, têm pessoas que entendem e falam mais de duas línguas. As crianças até os seis anos de idade 
são consideradas como monolíngues em língua materna, pois não entendem e não falam português.

A história dos Apyãwa ao longo do século passado é marcada por uma impressionante trajetória, um povo indígena que correu o risco de deixar fisicamente de existir, mas que foi capaz de criar caminhos de sobrevivência digna e sempre lutando para manter sua cultura e língua vivas. Segundo historiadores Apyãwa, as epidemias de novas doenças (em especial, o sarampo e a gripe), durante a primeira metade do século $\mathrm{XX}$, foram os principais fatores que reduziram os Apyãwa a uma população de menos de cinquenta pessoas. E não os confrontos de guerra contra inimigos Kaiapó, como muitos autores destacam em seus trabalhos, nas dissertações, nas monografias etc.

É importante frisar que, quando ocorreu o último confronto com os inimigos Kayapó em 1947, os Apyãwa já se encontravam bastante reduzidos em decorrência das sucessivas epidemias que os abateram desde os anos dos primeiros contatos com os não indígenas. Portanto, Apyãwa sempre discorda quando se trata que a redução de população foi causada pelos ataques dos Kaiapó.

Mesmo passando por diversas situações negativas o povo Apyãwa nunca deixou de lutar pela sobrevivência cultural e linguística, assim conseguindo preservar o conhecimento tradicional até hoje. Preservar a língua e a cultura ainda é uma expressão recorrente e central até hoje nas discussões dos Apyãwa mais adultos. Acontece que a população jovem tem posição oposta, o interesse maior de aprender a língua e a cultura da sociedade nacional. Ao invés de se contraporem à forte entrada de língua portuguesa vem submetendo a língua a uma situação delicada.

\section{Situação Sociolinguística do povo Apyãwa da Terra Indígena Urubu-Branco}

A Terra Indígena Urubu-Branco, por nós denominada Yrywo'ywãwa "local onde urubu branco bebe", atinge uma extensão de 167.533 hectares e está localizada entre os municípios de Santa Terezinha, Porto Alegre do Norte e Confresa, no estado do Mato Grosso. É demarcada, homologada e registrada no cartório. É nesta área que se concentra a maior parte da população Apyãwa distribuída 
em sete aldeias: Tapi'itãwa, Tapiparanytãwa, Towajaatãwa, Wiriaotãwa, Myryxitãwa, Akara’ytãwa e Inataotãwa, construída recentemente. Desse total uma pequena população constitui uma única aldeia chamada Majtyritãwa, na Área Indígena Tapirapé/ Karajá, onde também estão as aldeias Karajá Itxala e Hawalora.

Os Apyãwa de todas essas aldeias falam a língua Apyãwa como sua primeira língua. Aliás, essa é a primeira língua adquirida pelas crianças e é mais falada pela população. A grande maioria da população domina também o português como segunda língua. Nesse sentido, o estudo nos aponta que as comunidades de todas as aldeias Apyãwa são consideradas bilíngues em Tapirapé e português.

Em algumas famílias, no caso de casamento interétnico, têm pessoas que entendem e falam mais de duas línguas. "Trata-se das famílias que em função de casamento com outras etnias como Karajá, Kaiabi, Javaé, Avá-Canoeiro e Bakairi são trilíngues que, além de Tapirapé e português falam essas línguas respectivamente" (Paula, 2014). Hoje também tem alguns casais formados por mulheres não indígenas. Esses casais normalmente se comunicam em português e moram na cidade. No entanto, os filhos que poderão vir desses casais provavelmente serão monolíngues na língua portuguesa.

Até os seis anos, as crianças Apyãwa só falam a língua Apyãwa, portanto são monolíngues. A partir desta idade começam adquirir e entender um pouquinho da língua portuguesa tanto na escola quanto fora dela. A aquisição do português fora da escola acontece de maneira informal através de contatos com os falantes do português ou através dos meios de comunicação presentes nas aldeias, como televisão, celular, mp3, câmera digital, computador, notebook etc. Já através da escola o português é adquirido de modo mais formal.

De uma maneira geral, as crianças começam ter contato maior com o português a partir de $2^{\circ}$ ciclo $3^{\circ}$ fase do ensino fundamental. Nesta fase de ensino a escola Apyãwa oferece, além de língua materna, outras disciplinas como português, ciências da natureza, matemática, geografia e história, conduzidas pelos próprios Apyãwa. O fato é que o material utilizado nesta fase quase todo é escritos nesta língua.

As crianças dos casais formados com outras etnias, de modo geral, desde pequenas têm contato com as duas línguas, utilizadas pelos pais para se comunicarem, porque cada um fala com a criança na sua língua materna. E, muitas vezes, desde pequenas, essas 
crianças convivem simultaneamente com as três línguas. Além de duas línguas indígenas, têm o português, que é usado pelos seus pais.

Este fato acontece mais com os casais formados pelos Apyãwa com Karajá ou Javaé, porque linguisticamente são bem diferentes. O Karajá e o Javaé são línguas Macro-Jê e o Tapirapé é uma língua Tupi-Guarani. O mesmo acontece também com o casal formado com o Bakairi. Ao contrário disso, os casais formados com os Kaiabi muitas vezes se comunicam exclusivamente na língua Apyãwa, porque são línguas muito parecidas. As duas línguas são Tupi-Guarani e isso ajuda aprender a língua Apyãwa com muita facilidade.

Mas percebe-se que a língua Apyãwa é soberana em todos os domínios sociais do cotidiano e nos espaços especializados no interior do território Apyãwa. Apresento a seguir, línguas usadas por cada pai e mãe:

1. Casal formado por homem Apyãwa e mulher Apyãwa - a língua usada com as crianças é Apyãwa.

2. Casal formado por homem Apyãwa e mulher Karajá - as línguas usadas com as crianças são Apyãwa e Karajá.

3. Casal formado por mulher Apyãwa e homem Karajá - as línguas usadas com crianças são Apyãwa e Karajá.

4. Casal formado por homem Apyãwa e mulher Javaé - as línguas usadas com as crianças são Apyãwa e Javaé.

5. Casal formado por homem Apyãwa e mulher AváCanoeiro - a língua usada com as crianças é Apyãwa.

6. Casal formado por homem Apyãwa e mulher Kaiabi - as línguas usadas com as crianças são Apyãwa e Kaiabi.

7. Casal formado por mulher Apyãwa e homem Kaiabi - as línguas usadas são Apyãwa e Kaiabi.

A língua Apyãwa não só é a primeira língua adquirida como é também a mais falada pela população dentro e fora das nossas aldeias. Ela é a língua mais utilizada na comunicação entre os Apyãwa, nas famílias, nas práticas educativas, nos trabalhos, nas cerimônias e rituais, na pescaria, caçada etc. e até mesmo fora delas, 
principalmente quando saem para estudar, no tratamento de saúde, na reunião na cidade etc. É também a mais falada nas instituições públicas presentes nas aldeias como escola e posto de saúde, pois a maioria dos funcionários é Apyãwa.

Mesmo nos assuntos que envolvem a cultura não indígena ela é a língua preferida pela população. Isso é fundamental para fortalecimento e valorização de sabedorias nela guardadas. E a língua portuguesa é utilizada somente para comunicação com as pessoas que não falam a língua Apyãwa. Ou seja, o uso dessa língua depende praticamente da situação e dos interlocutores.

O que me deixa bastante preocupado é que a língua portuguesa está cada vez mais presente nas aldeias, pois tudo que chega à aldeia é escrito em português. Por exemplo, alimentação, objetos e instrumentos, transportes, roupas, meio de comunicação etc. E, evidente, que com eles entraram outras palavras que estão relacionadas às suas utilizações. Estas entram causando impacto muito grande na estrutura das falas, porque ocupam lugares das palavras da língua Apyãwa. Sendo assim, muitas delas estão em desusos, porque são substituídas pelas palavras não indígenas. Para aquilo que adquirimos por necessidades (alimentação, objetos e instrumentos, transportes, roupas, meio de comunicação etc) foram criadas novas palavras com outros significados em Apyãwa e estão em usos nas comunidades.

A pesquisa nos revela que os meninos estão aprendendo a língua portuguesa muito mais cedo em relação às meninas. Pois eles têm mais contato com a língua portuguesa, principalmente através dos meios de comunicação mencionados nos parágrafos anteriores. Também porque têm mais liberdade de ter acesso a essas coisas, recebem incentivos e motivações dos pais para aprender português.

A idéia que os pais têm de seus filhos é que cresçam falando bem em língua portuguesa para saber dialogar com os governantes, a fim de resolverem as questões territoriais, educação e saúde. Isso porque na cultura Apyãwa, normalmente, quem sai para cidade, em defesa dos seus direitos são homens. Já as meninas são mais dedicadas às atividades culturais, como confecção de pulseiras de miçanga, tecelagem, colares, brincos e outros artefatos.

Algumas décadas atrás, essa realidade era bem diferente. Os jovens Apyãwa aprendiam o português somente na escola, pois naquela época todos tinham total dedicação às práticas culturais, por isso os jovens de até 15 anos eram monolíngues em língua materna. 
Acontece que na atualidade os contatos com a sociedade não indígena são muito frequentes, pois a cidade de Confresa fica muito próxima. Como bem afirma Paula (2014)

a sede do município dista apenas $30 \mathrm{~km}$ da área indígena, o que facilita um intenso contato com a cidade. Os professores, agentes de saúde e aposentados necessitam deslocar-se até a agência bancária a fim de receberem seus vencimentos. Os benefícios concedidos pelo governo federal, como Bolsa Família e o Auxílio Maternidade, também são recebidos na cidade. No comércio local, os Tapirapé fazem compras de alimentos, roupas, calçados e outros utensílios. No hospital recebem atendimento médico e, por vezes, são internados. $\mathrm{O}$ pólo de saúde indígena também está localizado na cidade e há vários Tapirapé atuando como funcionários da SESAI (Secretaria Especial de Saúde Indígena). A direção da escola tem que se dirigir constantemente à assessoria pedagógica, instância da Secretaria de educação de Mato Grosso, para encaminhar documentos da escola. Além do mais, há uma estrada estadual que atravessa a Área Indígena Urubu Branco, possibilitando o trânsito de muitos não índios pelas aldeias. Há um ônibus fazendo uma regular entre Santa Terezinha e Confresa três vezes por semana, passando por duas aldeias dentro da área indígena.

Um dos principais fatores que levam as crianças a aprenderem o português mais cedo é a televisão e o celular. Com a televisão e o celular nas aldeias as crianças e jovens Apyãwa não só estão aprendendo português mais cedo, mas deixando de praticar muitos elementos culturais do povo. As brincadeiras tradicionais, por exemplo, como tytykãwa 'amarelinha', mani'akawy ' brincando em roda roda', xapakani 'gavião', xapie'ema 'pega pega', tapire 'ore'o e xamainãwa 'treinamento para ser um bom atirador de arco e flecha', que faziam parte dos cotidianos das crianças, estão deixando de existir. Juntos com elas, com certeza, deixando de usar as palavras que se referem a essas brincadeiras.

Essas brincadeiras são substituídas pelos esportes não indígenas como futebol e voleibol, desenhos animados, filmes de terrores adquiridos através do programa de televisão e pelos jogos 
baixados através de aplicativos de celulares. A televisão e o celular hoje ocupam mais tempo tanto das crianças quanto dos jovens Apyãwa. E tudo que se aprende por meio dela são experimentados na comunidade.

Com essa nova realidade muitas outras práticas culturais dos Apyãwa estão perdendo seus espaços e com isso a língua Apyãwa, hoje, vive uma situação de conflito muito grande com a língua maira (Português). A língua Apyãwa não está sendo utilizada legitimamente como deve, isto é, nas falas de grande maioria das pessoas aparecem muitas palavras da língua portuguesa ocupando espaço que é da língua Apyãwa. Muitas palavras da língua portuguesa já foram incorporadas nessa língua e fazendo parte da conversa do dia a dia da comunidade. Sendo assim, ela está sofrendo muita mudança na estrutura sintática e aos poucos perdendo sentido na comunidade.

\section{Situações de Uso da Língua Apyãwa hoje}

A nossa língua materna vive uma realidade muito complicada na atualidade. Apesar de ser falada em todas as comunidades Apyãwa, ela sofre impacto muito grande do português, a dificuldade de comunicar-se exclusivamente na nossa língua é muito grande. Em sua grande maioria, a população jovem da comunidade Apyãwa, ao invés de procurar falar adequadamente na nossa língua, busca a maneira de inserir mais o português nas suas conversas do dia a dia. Por exemplo, em vez de: pexe xikaro 'vamos almoçar', os mais jovens falam "pexe xi-almoçar", trocando karo por 'almoçar'; no lugar de pexe xixemaryj'yg 'vamos brincar', "pexe xi-brincar", substituindo xemaryj'yg por 'brincar'; em vez de pemoagato 'organizam', "peorganizar" moagato, perdendo espaço para 'organizar'. E assim sucessivamente.

Ao invés de aprender e se preocupar em conhecer valores socioculturais e linguísticos, as juventudes dedicam-se às práticas adotadas da cultura não indígena. E junto com essas práticas com certeza valorizando as palavras que se referem a elas. Enquanto surgem as novas realidades nas aldeias outros se deslocam, certamente deixando de existir no espaço. E assim muitas práticas culturais do nosso povo deixaram de existir, por exemplo, xamainãwa "treinamento para ser um bom atirador de arco e flecha", xajãwa "técnica de derramar sangue ruim e tornar a pessoa ser um bom 
lutador ou corredor" etc. E, óbvio, carregando consigo as palavras com elas relacionadas inclusive as técnicas de suas confecções.

É muito importante destacar que a língua sempre acompanha o movimento dos seus falantes, onde eles forem ela sempre está presente. Se ela não está presente, é porque deixou de existir. Ela só tem força quando existem saberes vivos. Quando o saber de uma cultura começa ter mudança, muda e diminui também o uso das palavras. $\mathrm{E}$, quando uma prática desaparece, as palavras relacionadas a essa prática também morrem. Onde têm mais mudanças da cultura, mais desusos das palavras. Isto está acontecendo com a língua e a cultura do nosso povo. Se a nossa língua e a cultura estão enfraquecendo é porque o universo cultural passa por uma transformação, mas pouco favorável à nossa luta.

Antigamente os Apyãwa comunicavam-se exclusivamente na sua língua, nem sequer usavam uma palavra portuguesa. Utilizavam sua língua na sequência estrutural sem nenhuma dificuldade. Naquela época os nossos antigos dedicavam-se também às atividades específicas, com os instrumentos próprios, consumiam seus alimentos típicos, realizando festas, rituais etc. Contudo, a nossa língua e a cultura permaneciam fortes e sadia. Não havia necessidade de emprestar como acontece hoje. Lembrando também que naquela época não havia nenhuma presença do português na aldeia.

$\mathrm{E}$, quando houve o contato com a sociedade maira, o nosso povo começou a utilizar ou emprestar as coisas deles. Começou empestar as coisas básicas, o que eles também forneciam para nossos antigos como facão, machado, foice, café, açúcar etc. Com isso entraram os nomes e outras palavras relacionadas a eles. E assim iniciou-se a entrada do português na nossa cultura.

Desde então começou o conflito entre a nossa língua e a língua portuguesa. E hoje a situação está se agravando, muitas palavras da nossa língua se deslocaram, sendo substituídas pelo português. Sendo assim a estrutura da nossa língua sofreu muitas mudanças por causa da influência do português.

É muito comum ouvir hoje a palavra portuguesa na fala do nosso povo, principalmente pelas juventudes. Algumas pessoas se dirigem praticamente em português, ou seja, inserem mais o português do que falar em Apyãwa. Outras ainda tentam falar exclusivamente na nossa língua e muitos, em vez de fazer o mesmo, tentam mais só colocar português na sua fala. Essas situações acontecem em 
vários espaços frequentados pelos Apyãwa como escola, reunião da comunidade, no jogo de futebol, na sala de televisão etc.

Veja alguns exemplos abaixo:

Neste exemplo apresento a fala de um professor na sala de aula, na etapa do Projeto Aranowa'yao "Novos Pensamentos ensino médio".

"ÃJ-TREGAR EKWE CADA UM PENOPE APOSTILHA PARA IAPAWO LEITURA E I-RESUMI-WO TEXTO, TÁ. MAS TEM QUE SER LEITURA SILENCIOSA, TÁ. QUALQUER COISA KE PE-SUBLINHAR PALAVRAS DESCONHECIDAS, PARA DEPOIS EMIGÃ I-RESOLVE-WO, TÁ. PEJ-TENTENDER TA'E? TUDO BÉM A'ERA MÕ, PODE A'ERA MÕ I-COMEÇAWO”.

(02)

No exemplo (02) apresento a fala de uma liderança na reunião da comunidade (barracão da comunidade). Nesta reunião a comunidade estava discutindo invasão da Terra Indígena UrubuBranco.

"NAXIXE-ORGANIZA-J 'Ã XEREKAWO QUE XEREXE-ORGANIZA-WO KWI, A'E TANÃ TODO MUNDO JUNTO XIKA XERE-LUTA-WO KWI. EMANYN TANÃ EKWE XI-PERDER XEREYWY. CADA VEZ SÓ IKE MESMA PESSOA XE XANEYWY PE RANÕ. SE EKWE XIAMOLECER IXOPE XEREKAWO A'E EKWE SEMPRE NYN A-ACONTECER AKAWO”. 
Este exemplo compõe informações de como os jovens Apyãwa falam durante o jogo de futebol.

'PRIMEIRA RODADA WE 'Ã A-COMEÇAR, A'ERE XOWE EKWE SEGUNDA RODADA. SEGUNDA RODADA PAWIRE EKWE ELIMINATÓRIA XYREAGY. NATYWI EKWE SALDO DE GOL, QUEM EKWE I-GANHAR A'EGÃ EKWE AXE-CLASSIFICAR".

"E-APROVEITAR OPORTUNIDADE KWI XYRE, EPE XANE CHANCE KWI. OPA, FALTA KWI PROFESSOR, TEM QUE IEXÃGA DOIS LADO KWI E'I. NERE-APITA-J EPE EKAWO ARE-LADO KATY EKAWO KWI LADRÃO”.

"E-ACREDITAR MI CRUZAMENTO RE KWI XYRE. PEDOMINAR BOLA PEE RANÕ KWI MEIO CAMPO AGY, SÓ BALÃO XE “ ̃ PEREKA”.

Aqui apresento as conversas de crianças, jovens e adultos na sala de televisão.

“E-LIGAR TV XEREXEWE ATAI, XIEXÃK JORNAL.
IE EKWE AJXAMATÃT CARROSSEL. JORNAL EKWE
XIEXÃK PORQUE MI CARROSSEL PEMA'E SÓ BESTEIRA
RE XE”.
"PEXE XIEXÃK HOMEM DE FERRO KWI. HOMEM DE FERRO PÃ MI I-FORTE YGOO WÃ. NEM MI NA-SENTIR AMAXOMÃWA. I MI NÃO É POUCO IPARA-SALVAR AKAWO".


Dessa forma o português entra ocupando espaço das nossas palavras e ganhando privilégio dos próprios Apyãwa. Portanto, a nossa língua sofre desvalorização, perdendo seu espaço para o português.

\section{Empréstimos e a Invasão da Língua Apyãwa}

O empréstimo é o ato de emprestar e é sinônimo de pegar uma coisa uns dos outros. Normalmente acontece quando necessitamos de algo que não possuímos. E isso acontece em qualquer sociedade do mundo a partir do contato entre as culturas. E é um costume que está presente em qualquer cultura.

O empréstimo da língua acontece justamente desta forma, a partir do momento em que acontece o contato entre duas culturas. Ela é resultado de troca de saberes, de objetos, de produtos etc. A partir da entrada e de uso desses elementos é que as palavras começam entrar numa cultura que está emprestando. A primeira palavra que entra junto com os elementos são os nomes e depois as outras palavras que estão relacionadas a estes saberes. Este é a principal porta de entrada de outras línguas, linguisticamente chamado de empréstimo linguístico. Neste sentido podemos então entender que o empréstimo da língua acontece quando por necessidade adotamos palavras a partir do uso de objetos, instrumentos, alimentação etc de outra cultura.

Desse modo a nossa língua começou emprestar as palavras da língua portuguesa desde quando começou o primeiro contato com a sociedade maira. Quando começou o contato com os Maira, o nosso povo começou a utilizar instrumentos, roupas, alimentação e outras coisas que foram trazidos por eles. E sem dúvidas com a entrada dessas coisas entraram também os nomes desses novos elementos. Mas muitos desses elementos receberam nomes na língua Apyãwa, como aypyyro (camisa), owyropoko (calça), pyyro (calçado), xy (machado), kyxeo (facão), kyxe (faca), xyapãra (foice), xyporore (enxada), xa'e (panela) etc.

Este tipo de empréstimo, que é semântico, de algum modo enriquece os nossos vocábulos, porque a língua recebe novas palavras, que são compostas a partir da estrutura de nossa língua mesmo. Mas por outro lado deixamos de utilizar aquilo que era da nossa cultura. Esse é o motivo pelo qual deixamos de utilizar paraxi 
na confecção de flecha, de utilizar xaj'oma para construir panela de barro, machado de pedra etc.

Hoje temos muito mais coisas emprestadas da sociedade Maira. Temos energia nas nossas aldeias e com ela entraram tecnologias como celular, filmadora, câmeras digitais, computador, notebook, televisão, geladeiras etc. Consumimos cada vez mais alimentos industrializados, praticamos mais esportes não indígenas e deixando de praticar o que é da nossa cultura. E com tudo isso as palavras da nossa língua estão se deslocando.

A invasão da língua é sinônima de guerra ou conflito linguístico. Acontece quando duas línguas se encontram com mais frequência. O mais forte entra expulsando as palavras do seu terreno, causando deslocamento de tal língua. Este processo é inicial e pode chegar até o desaparecimento de uma língua.

É resultado de palavras emprestadas não por meio de objetos, mas sim por interesse dos próprios falantes de uma língua. Aquelas palavras que, ao invés de nossa própria língua, pegamos de outra língua e usamos no meio das nossas falas, priorizando e substituindo as palavras da nossa língua no nosso dia a dia. Isto é chamado de invasão da língua. Neste processo uma língua acaba subordinandose a outra, causando perda gradual de uma língua.

Esta é uma realidade que está acontecendo com todas as línguas do Brasil. Com a nossa língua não é diferente, usamos muitas palavras emprestadas da língua portuguesa nas nossas falas. É muito comum ver e ouvir isso acontecer no discurso do dia a dia, principalmente nas falas de jovens, profissionais de educação, de saúde e de lideranças Apyãwa. E com isso as palavras que estão sendo substituídas pelo português estão perdendo suas forças e claro perdendo seus espaços. Essas palavras estão sendo usadas sem nenhuma consideração dos objetos e nem por falta de palavras na nossa língua. Portanto, é por interesse próprio de substituir nossas palavras.

A seguir apresento trabalho dos professores da língua Apyãwa sobre estas situações. 


\section{Trabalhos dos Professores Apyãwa para}

\section{Fortalecimento da Língua Materna}

Em primeiro lugar, quero destacar que a preocupação dos professores sobre a língua Apyãwa cada vez é maior, pois está claro que a mudança dela no uso da comunidade está em velocidade. Se não houver uma política efetiva para sustentar a vida dessa língua, estamos prestes a perder o universo cultural em curto prazo. Sabemos que para ter conhecimento vivo, em primeiro lugar, a língua precisa estar viva, pois ela é principal veículo de transmissão de valores culturais.

Mas sabemos também que a língua para continuar viva precisa da vontade dos falantes, pois eles é quem são responsáveis pelas suas utilidades e pela manutenção no universo. Caso contrário, ela some pouco a pouco até morrer. É nessa situação que a nossa língua Apyãwa se encontra, pois já desapareceram muitas palavras e muitas estão sendo substituídas pelas palavras do português.

Nesse sentido, a discussão sobre política de valorização da língua Apyãwa na escola começou a ser pensada e criada com intuito de conscientizar e despertar o desejo das juventudes no uso adequado da língua materna. Em cada encontro pedagógico os professores debatem e discutem a questão linguística, em busca de mecanismo de trabalho que ajude no fortalecimento de valores epistêmicos.

O que também mudou é que hoje nesse trabalho são envolvidos todos os professores de todas as áreas de conhecimentos. Antigamente este trabalho era feito somente pelos professores da área de ciências da linguagem e os professores de outras áreas de conhecimentos procuravam não participar das atividades linguísticas, porque entendiam que este era um assunto para ser trabalhado somente na aula de língua Apyãwa. São essas pessoas que contribuíam de alguma forma com a incorporação do português na sua fala do dia a dia, como está apresentada nos exemplos acima. Sendo assim, os trabalhos não mostravam resultados na comunidade.

Mas o que está sendo feito hoje é muito importante, todos os professores com muita preocupação sobre a manutenção e fortalecimento da língua materna. E assim a língua Apyãwa está sendo valorizada em todas as áreas de conhecimentos na escola. O professor comunica-se com seus alunos procurando não inserir nenhuma palavra portuguesa na sua fala. As explicações de todas 
as atividades desenvolvidas na escola acontecem na língua materna sem precisar misturar o português na fala. Assim também os alunos fazem na hora de apresentação de trabalhos de seus trabalhos.

O mais importante no trabalho de professores é a criação de novas palavras na língua Apyãwa para todas as palavras emprestadas presentes nas aldeias. Essas palavras são apresentadas na assembléia da comunidade onde são discutidas e aprovadas para serem utilizadas pelo povo. Além disso, estão sendo feitas várias outras ações para as práticas e valorização como trabalho na roça, pescaria com timbó, realização de rituais, manejo agro florestal etc. Esses trabalhos também são organizados junto com a comunidade.

A seguir apresento algumas palavras novas que foram criadas na nossa língua para objetos que são da cultura não indígena.

(05) Palavras novas criadas para objetos, instrumentos, móveis, transportes e alimentação

\begin{tabular}{|l|l|l|}
\hline Palavras em Apyãwa & $\begin{array}{c}\text { Palavras em } \\
\text { Português }\end{array}$ & \multicolumn{1}{|c|}{ Estrutura Morfológica } \\
\hline Arapatoxiga & Açúcar & $\begin{array}{l}\text { Arapato-xig-a = rapadura-branca- } \\
\text { nominalizador } \\
\text { raiz }+ \text { raiz }+ \text { sufixo }\end{array}$ \\
\hline Temi'omamieãwa & Alho & $\begin{array}{l}\text { Temi'o-ma-mie-ãwa }= \\
\text { Comida-causativizador-cheiro- } \\
\text { nominalizador } \\
\text { raiz }+ \text { causativizador }+ \text { raiz }+ \\
\text { sufixo }\end{array}$ \\
\hline Yroperynoo & Antena \\
Parabólica & $\begin{array}{l}\text { Yrope-ryn-oo }=\text { peneira-parece- } \\
\text { aumentativo } \\
\text { raiz }+ \text { raiz }+ \text { sufixo }\end{array}$ \\
\hline Paraxiakwa'akãwa & Apontador & $\begin{array}{l}\text { Paraxi-akwa-ak-ãwa }=\text { lápis- } \\
\text { ponta-afinar-nominalizador } \\
\text { raiz }+ \text { raiz }+ \text { raiz }+ \text { sufixo }\end{array}$ \\
\hline
\end{tabular}




\begin{tabular}{|c|c|c|}
\hline Palavras em Apyãwa & $\begin{array}{c}\text { Palavras em } \\
\text { Português }\end{array}$ & Estrutura Morfológica \\
\hline Ywytoro'yyga & $\begin{array}{l}\mathrm{Ar} \\
\text { Condicionado }\end{array}$ & $\begin{array}{l}\text { Ywyto-ro’yyg-a = vento-frio- } \\
\text { nominalizador } \\
\text { raiz + raiz + sufixo }\end{array}$ \\
\hline Ywyrapexygãwa & Arquivo & $\begin{array}{l}\text { Ywyrape-xyg-ãwa = papel- } \\
\text { guardar-nominalizador } \\
\text { raiz + raiz + sufixo }\end{array}$ \\
\hline Pepiywipyra & Asfalto & $\begin{array}{l}\text { Pe-piyw-ipyr-a = estrada-liso- } \\
\text { feito-nominalizador } \\
\text { raiz + raiz + raiz + sufixo }\end{array}$ \\
\hline Xaokãwa & Banheiro & $\begin{array}{l}\text { Xaok-ãwa = banhar- } \\
\text { nominalizador } \\
\text { Raiz + sufixo }\end{array}$ \\
\hline Xetyryna, Xetyki & Batatinha & $\begin{array}{l}\text { Xety-ryn-a = batata-parece- } \\
\text { nominalizador } \\
\text { raiz + raiz + sufixo }\end{array}$ \\
\hline Porakeryni & Bateria & $\begin{array}{l}\text { Porake-ryn-i = peixe elétrico- } \\
\text { parece-diminutivo } \\
\text { raiz + raiz + sufixo }\end{array}$ \\
\hline Koroxo & Bolo & $\begin{array}{l}\text { Koroxo = bolo } \\
\text { Raiz }\end{array}$ \\
\hline Xepikytykãwa & Bucha & $\begin{array}{l}\text { Xe-pi-kytyk-ãwa }=1^{\mathrm{a}} \\
\text { pessoa singular-pele-lavar- } \\
\text { nominalizador- } \\
\text { Prefixo + raiz + raiz + sufixo }\end{array}$ \\
\hline Ma'epapaawapiãwa & Calculadora & $\begin{array}{l}\text { Ma’e-papa-aw-api-ãwa = coisa- } \\
\text { contar-nominalizador-bater- } \\
\text { nominalizador } \\
\text { raiz + raiz + sufixo + raiz + sufixo }\end{array}$ \\
\hline
\end{tabular}




\begin{tabular}{|c|c|c|}
\hline Palavras em Apyãwa & $\begin{array}{c}\text { Palavras em } \\
\text { Português }\end{array}$ & Estrutura Morfológica \\
\hline Xaykwaapãwa & Calendário & $\begin{array}{l}\text { Xay-kwaap-ãwa }=\text { lua-saber- } \\
\text { nominalizador } \\
\text { raiz + raiz + sufixo }\end{array}$ \\
\hline Mytemekwãwa & Cama & $\begin{array}{l}\text { Mytem-ekwãwa = girau-rede } \\
\text { raiz }+ \text { raiz }\end{array}$ \\
\hline Apinyro, Akygyro & Capacete & $\begin{array}{l}\text { Apin-yro = cabeça-invólucro } \\
\text { Akyg-yro = testa-invólucro } \\
\text { raiz + raiz }\end{array}$ \\
\hline Xexagakaãwa & Consulta & $\begin{array}{l}\text { Xe-xag-aka-ãwa }=1^{a} \text { pessoa } \\
\text { singular-olhar-deixar- } \\
\text { nominalizador } \\
\text { Prefixo + raiz + raiz +sufixo }\end{array}$ \\
\hline Temi'omamieãwa & Cebola & $\begin{array}{l}\text { Temi'o-ma-mie-ãwa }= \\
\text { comida-causativizador-cheiro- } \\
\text { nominalizador } \\
\text { raiz + causativizador + raiz + } \\
\text { sufixo }\end{array}$ \\
\hline Xe'egawi & Celular & $\begin{array}{l}\text { Xe'eg-aw-i = falar- } \\
\text { nominalizador-diminutivo } \\
\text { Raiz + sufixo + sufixo }\end{array}$ \\
\hline Yhaj'i & Cerveja & $\begin{array}{l}\mathrm{y} \text {-haj-i = água-azeda-diminutivo } \\
\text { raiz + raiz + sufixo }\end{array}$ \\
\hline Ma'ekotyja & Chave & $\begin{array}{l}\text { Ma'e-kotyj-a = coisa-trancar- } \\
\text { nominalizador } \\
\text { raiz + raiz + sufixo }\end{array}$ \\
\hline Ywyrapeapiãwa & Computador & $\begin{array}{l}\text { Ywyrape-api-ãwa = papel-bater- } \\
\text { nominalizador } \\
\text { Raiz + raiz + sufixo }\end{array}$ \\
\hline Tataxany & Combustível & $\begin{array}{l}\text { Tata-xany }=\text { fogo-óleo } \\
\text { raiz }+ \text { raiz }\end{array}$ \\
\hline
\end{tabular}




\begin{tabular}{|c|c|c|}
\hline Palavras em Apyãwa & $\begin{array}{c}\text { Palavras em } \\
\text { Português }\end{array}$ & Estrutura Morfológica \\
\hline Xeakymamykãwa & Creme & $\begin{array}{l}\text { Xe-aky-mamyk-ãwa }=1^{\mathrm{a}} \\
\text { pessoa singular-testa-passar- } \\
\text { nominalizador } \\
\text { Prefixo + raiz + raiz + sufixo }\end{array}$ \\
\hline Te'omarexakãwa & Data Show & $\begin{array}{l}\text { Te'omar-exak-ãwa = trabalho- } \\
\text { olhar-nominalizador } \\
\text { raiz + raiz + sufixo }\end{array}$ \\
\hline Iawa'ima'e'ywa & DVD & $\begin{array}{l}\text { I-awa-'i-ma'e-yw-a = } 3^{\mathrm{a}} \text { pessoa } \\
\text { singular-redondo-diminutivo- } \\
\text { coisa-pé } \\
\text { Prefixo + raiz + sufixo + raiz + } \\
\text { raiz }\end{array}$ \\
\hline Porakerynoo & Energia & $\begin{array}{l}\text { Porake-ryn-oo = peixe elétrico- } \\
\text { parece-aumentativo } \\
\text { raiz + raiz + sufixo }\end{array}$ \\
\hline Maranowaxygãwa & Envelope & $\begin{array}{l}\text { Maranowa-xyg-ãwa = recado- } \\
\text { colocar-nominalizador } \\
\text { Raiz + raiz + sufixo }\end{array}$ \\
\hline Tapawã & Fio & $\begin{array}{l}\text { Tapawã = fio } \\
\text { Raiz }\end{array}$ \\
\hline Marakarenopãwa & Fone & $\begin{array}{l}\text { Maraka-r-enop-ãwa = música- } \\
\text { relacional-escutar-nominalizador } \\
\text { Raiz + prefixo + raiz + sufixo }\end{array}$ \\
\hline Ma'emaro'yygãwa & Freezer & $\begin{array}{l}\text { Ma'e-ma-ro'yyg-ãwa = } \\
\text { coisa-causativizador-gelar- } \\
\text { nominalizador } \\
\text { Raiz + causativizador + raiz + } \\
\text { sufixo }\end{array}$ \\
\hline
\end{tabular}




\begin{tabular}{|c|c|c|}
\hline Palavras em Apyãwa & $\begin{array}{c}\text { Palavras em } \\
\text { Português }\end{array}$ & Estrutura Morfológica \\
\hline Xema'awatyãwa & Gel & $\begin{array}{l}\text { Xe-ma-'aw-aty-ãwa = } 1^{\mathrm{a}} \text { pessoa } \\
\text { singular-causativizador-cabelo- } \\
\text { duro-nominalizador } \\
\text { Prefixo + causativizador + raiz + } \\
\text { raiz + sufixo }\end{array}$ \\
\hline Ma'emaro'yygãwa & Geladeira & $\begin{array}{l}\text { Ma'e-ma-ro'yyg-ãwa = } \\
\text { coisa-causativizador-gelar- } \\
\text { nominalizador } \\
\text { Raiz + causativizador + raiz + } \\
\text { sufixo }\end{array}$ \\
\hline Yxema'itã & Gelo & $\begin{array}{l}\text { y-xe-ma-itã }=\text { água-morfema } \\
\text { reflexivo-causativo-pedra } \\
\text { raiz }+ \text { prefixo }+ \text { causativizador }+ \\
\text { raiz }\end{array}$ \\
\hline Xa'exygãwa & Guarda-louça & $\begin{array}{l}\text { Xa'e-xyg-ãwa = panela-guardar- } \\
\text { nominalizador } \\
\text { raiz + raiz + sufixo }\end{array}$ \\
\hline Tyroxygãwa & Guarda-roupa & $\begin{array}{l}\text { Tyro-xyg-ãw-a = roupa-guardar- } \\
\text { nominalizador } \\
\text { raiz + raiz + sufixo }\end{array}$ \\
\hline Ma'ero’yygyro & Isopor & $\begin{array}{l}\text { Ma'e-ro'yyg-yro = coisa-gelar- } \\
\text { invólucro } \\
\text { raiz + raiz + raiz }\end{array}$ \\
\hline Awyrapyakwãra & Janela & $\begin{array}{l}\text { Awyr-apya-kwãr-a = casa- } \\
\text { ouvido-buraco-nominalizador } \\
\text { raiz + raiz + raiz + sufixo }\end{array}$ \\
\hline Tataeny & Lâmpada & $\begin{array}{l}\text { Tata-eny }=\text { fogo-luz } \\
\text { raiz }+ \text { raiz }\end{array}$ \\
\hline
\end{tabular}




\begin{tabular}{|c|c|c|}
\hline Palavras em Apyãwa & $\begin{array}{c}\text { Palavras em } \\
\text { Português }\end{array}$ & Estrutura Morfológica \\
\hline Tyroremyjnãwa & Mala & $\begin{array}{l}\text { Tyro-r-emyjn-ãwa = roupa- } \\
\text { relacional-levar-nominalizador } \\
\text { raiz + prefixo + raiz + sufixo }\end{array}$ \\
\hline Xe'egãwa & Microfone & $\begin{array}{l}\text { Xe'eg-ãwa = falar-nominalizador } \\
\text { raiz }+ \text { sufixo }\end{array}$ \\
\hline Xakopepayma & Mochila & $\begin{array}{l}\text { Xako-pepa-yma = saco-asa-alça } \\
\text { raiz + raiz + raiz }\end{array}$ \\
\hline Tatayakopy & Moto & $\begin{array}{l}\text { Tata-ya-kopy }=\text { fogo-meio de } \\
\text { transporte-tornozelo } \\
\text { raiz + raiz + raiz }\end{array}$ \\
\hline Anoxa'i & Mouse & $\begin{array}{l}\text { Anoxa-'i }=\text { rato-diminutivo } \\
\text { raiz }+ \text { sufixo }\end{array}$ \\
\hline Marakaxygãwa & MP3 & $\begin{array}{l}\text { Maraka-xyg-ãwa = música- } \\
\text { guardar-nominalizador } \\
\text { raiz + raiz + sufixo }\end{array}$ \\
\hline Ywyrapeapiãwa & Notebook & $\begin{array}{l}\text { Ywyrape-api-ãwa = papel-bater- } \\
\text { nominalizador } \\
\text { raiz + raiz + sufixo }\end{array}$ \\
\hline Itaxoweã & Óculos & $\begin{array}{l}\text { Itaxow-eã = vidro-olho } \\
\text { raiz }+ \text { raiz }\end{array}$ \\
\hline Namio & Orelhão & $\begin{array}{l}\text { Nami-o = orelha-aumentativo } \\
\text { raiz }+ \text { sufixo }\end{array}$ \\
\hline Xa'epyejtãwa & Pia & $\begin{array}{l}\text { Xa'e-pyejt-ãwa = panela-lavar- } \\
\text { nominalizador } \\
\text { raiz + raiz + sufixo }\end{array}$ \\
\hline Awyramyxãwa & Quarto & $\begin{array}{l}\text { Awyra-myxãw-a = casa-divisa- } \\
\text { nominalizador } \\
\text { raiz + raiz + sufixo }\end{array}$ \\
\hline
\end{tabular}




\begin{tabular}{|c|c|c|}
\hline Palavras em Apyãwa & $\begin{array}{c}\text { Palavras em } \\
\text { Português }\end{array}$ & Estrutura Morfológica \\
\hline Yyxygãwa & Rodo & $\begin{array}{l}\text { y-yxyg-ãwa = água-jogar- } \\
\text { nominalizador } \\
\text { raiz + raiz + sufixo }\end{array}$ \\
\hline Apyjwarawi & Skyny & $\begin{array}{l}\text { Apywarawi = espécie de } \\
\text { cogumelo } \\
\text { Raiz }\end{array}$ \\
\hline Eixemamy & Sorvete & $\begin{array}{l}\text { Ei-xemamy }=\text { mel-derrete } \\
\text { raiz }+ \text { raiz }\end{array}$ \\
\hline Tekaeterexakãwa & Televisão & $\begin{array}{l}\text { Tekaete-r-exak-ãw-a = vivo- } \\
\text { relacional-olhar-nominalizador } \\
\text { raiz + prefixo + raiz + sufixo }\end{array}$ \\
\hline Xepimakygãwa & Toalha & $\begin{array}{l}\text { Xe-pi-makyg-ãwa }=1^{\mathrm{a}} \\
\text { pessoa singular-pele-enxugar- } \\
\text { nominalizador } \\
\text { Prefixo + raiz + raiz }+ \text { sufixo }\end{array}$ \\
\hline Itaxowyãra & Trem de ferro & $\begin{array}{l}\text { Itaxow-yar-a = ferro-meio de } \\
\text { transporte-nominalizador } \\
\text { raiz + raiz + sufixo }\end{array}$ \\
\hline Paxiãwa, Pexakaãwa & Vaso sanitário & $\begin{array}{l}\text { Paxi-ãwa = fezes-nominalizador } \\
\text { Raiz + sufixo }\end{array}$ \\
\hline Xepipexoãwa & Ventilador & $\begin{array}{l}\text { Xe-pi-pexo-ãwa }=1^{\mathrm{a}} \text { pessoa } \\
\text { singular-pele-soprar-nominalizdor } \\
\text { Prefixo }+ \text { raiz }+ \text { raiz }+ \text { sufixo }\end{array}$ \\
\hline
\end{tabular}

Normalmente os nomes dados a essas coisas são criados a partir das suas utilizações ou funções, formas e aparências de objetos. Por exemplo: a) paxi-ãwa 'vaso sanitário' (fezes-nominalizador - "lugar onde se fazem as fezes"); b) itaxow-yãra 'trem de ferro' (ferro-transporte - "transporte de ferro"); c) yrope-ryn-oo 'antena parabólica’ (peneira-quase-aumentativo “quase igualzão peneira”). Outros recebem nomes que já temos no nosso vocabulário, como 
anoxa'i 'ratinho', hoje é mouse também, segundo professores, porque o objeto se parece com rato. Assim como apyjwarawi 'tipo de cogumelo', nome dado para skyny, por ter aparência semelhante a uma espécie de cogumelo encontrado na região. Desta forma, são criados nomes para aquilo que de fora entrou nas aldeias Apyãwa.

A seguir apresento lista de algumas palavras emprestadas do português não por meio de objetos, mas sim por interesse dos próprios falantes da língua Apyãwa. Aquelas palavras que, ao invés de nossa própria língua, pegamos e usamos no meio das nossas falas, priorizando e substituindo as palavras da nossa língua no nosso dia a dia. 
(06) Algumas palavras emprestadas sem nenhuma consideração de objeto

\begin{tabular}{ll} 
LÍNGUA APYÃWA & PORTUGUÊS \\
Kwãra & Ano \\
A'ere & Até \\
Ama'ygeka & Atrapalhar \\
Aopy/Amaaron & Achar \\
Apyyro & Ajudar \\
Amatyryryk & Apertar \\
Ity'ity'i & Apressar \\
Axewayg & Aguentar \\
Aranowe'yma & Besta \\
Aoxekato & Bom/boa \\
Kwewekwewe & Cada vez \\
Axema'ygapyk & Confiar \\
Amataraip & Complicar \\
Anog/Aetyk & Deixar \\
Ipykapy & Demorar \\
Weraxewyt & Devolver \\
Ãra & Dia \\
Marywara & Doente \\
Ywyatãra & Dúvida \\
Amanajxepy & Emprestar \\
Axajxãk & Encontrar \\
Amatyneem & Encher \\
Apoenop & Entender \\
Amanaakãt & Enviar \\
Ake & Entrar \\
Amawa'yg & Enganar \\
Nayj/Aye'ym & Fácil \\
Ryna & Fraco \\
Marepy & Ganhar \\
& \\
\hline &
\end{tabular}


É importante ressaltar que já existiam e existem palavras em Apyãwa para essas palavras do português que estão sendo usadas no meio de nossas falas. Acontece que estão perdendo seus lugares e perdendo sentidos no universo. Esses tipos de empréstimos são chamados de invasão da língua, porque as palavras entram em conflitos com as outras, e as mais fortes terminam conquistando seus devidos lugares. Neste processo uma língua acaba subordinando-se a outra, causando perda gradual de uma língua, como é o caso da nossa. Muitas palavras Apyãwa se deslocaram. Outras podem também perder seus espaços futuramente, caso não tomemos providências necessárias e de imediatos.

\section{Considerações finais}

Considero este trabalho como início de estudos linguísticos, que poderá ser ampliado ao decorrer do tempo conforme o grau de escolaridade. É um assunto de suma importância para pensarmos a construção de um mecanismo de trabalho linguístico que possa de fato sustentar a vida de nossa língua Apyãwa, uma vez que ela sofre impacto muito grande da língua portuguesa.

A pesquisa nos mostra que ainda há deficiência muito grande na parte das atividades linguísticas feitas pelos professores Apyãwa, porque se notam claramente fortes presenças do português nas falas e nos discursos dos falantes. Em vez de falar propriamente na língua Apyãwa são incorporadas muitas palavras não indígenas nas falas, tornando-se o uso dela cada vez mais precária. É um caso que deve ser tratado com muita urgência e frequência com todos os falantes, porque nem todos têm noção da gravidade da situação pela qual a língua passa. Por isso, talvez procura não evitar a inserção do português quando fala. Caso contrário, corremos o risco de perder a língua em curto prazo.

Para muitos Apyãwa sua língua não se encontra em estado de emergência. Entende-se que ainda é fortemente falada em todos os domínios sociais, mas esquecem das entradas de mundos virtuais nas aldeias com as quais gerações mais novas estão mais envolvidas. Com isso muitas práticas culturais vêm perdendo sentidos nos espaços levando consigo as palavras que se referem a elas. Essas coisas não só ocupam lugar no espaço, mas transformam comportamentos das juventudes Apyãwa para uma realidade totalmente diferente da 
realidade Apyãwa, o que leva as juventudes a se distanciar das suas próprias atividades na comunidade.

Muito outros se recusam falar adequadamente na própria língua, alegando que não adianta porque estamos cercados pelo mundo não indígena. Portanto, o interesse de aprender o português é maior que a sua própria. É evidente que não podemos nos livrar dessas situações, mas também não podemos nos precipitar em aceitar tudo mesmo sabendo das consequências. Lembrando que a vida de uma língua é a base de um universo cultural. Quando uma língua se perde, tudo que por meio dela são feitas também desaparecem.

Portanto, se perdermos nossa língua, perderemos também tudo aquilo que faz parte da nossa cultura, porque a nossa língua não é apenas sistema de comunicação, mas, sim, um mundo em que se permite a natureza e o ser humano com as mesmas condições de viver. Sistema mundo que nos mantém contato com sobrenatural e que nos garante diferentes percepções e explicações do mundo.

Neste sentido o assunto aqui registrado mostra sua grande importância para resgate e fortalecimento de nossa língua, bem como para garantir nossa ciência e cosmologia. Contudo, deixo o meu trabalho pronto e disposto para qualquer sujeito analisar e acrescentar a pesquisa.

\section{Referência bibliográfica}

PAULA, Eunice Dias. A interculturalidade no cotidiano de uma escola indígena. Cadernos Cedes. Ano XIX, no 49, Dezembro, 1999. pp. 76-91.

PAULA, Eunice Dias. A língua dos Apyãwa-Tapirapé - na perspectiva da etnossintaxe. $1^{\mathrm{a}}$ ed. Campinas SP: Editora Curt Nimuendaju, 2014.

Recebido para publicação em julho de 2018. Aceito para publicação em julho de 2018. 